\title{
Microscopic investigation on concrete cured internally by using porous ceramic roof-tile waste aggregate
}

\author{
Azusa Shigeta ${ }^{1}$, Yuko Ogawa ${ }^{1}$, and Kenji Kawai ${ }^{1 *}$ \\ ${ }^{1}$ Department of Civil and Environmental Engineering Graduate School of Engineering, Hiroshima \\ University, 1-4-1 Kagamiyama, Higashi-Hiroshima, Hiroshima, Japan
}

\begin{abstract}
Porous ceramic roof-tile waste aggregate (PCA), which is a recycled material, is an effective internal curing material for concrete. Part of the aggregate is replaced with saturated internal curing material to supply internal water into the cement paste continuously. Internal water is effective to promote the hydration of cement paste, especially in concrete with a low water-to-cement ratio because external curing water cannot easily reach inside the concrete. It has been reported that PCA leads to an increase in compressive strength and the reduction of autogenous shrinkage of concrete. However, the effects of PCA in previous researches are different with regards to the experimental conditions and have not been evaluated sufficiently. Therefore, the present study aims to investigate the effect of internal water supplied from PCA microscopically. In the experimental program, a compressive strength test was conducted for 6 types of concrete with a W/C of 0.35 . The microhardness around the aggregate in the concrete was also measured to investigate the extent of the influence of the internal water supply. The results showed the possibility that microhardness of ITZ around PCA is improved by internal curing water supply and the compressive strength of concrete is also improved by using PCA.
\end{abstract}

\section{Introduction}

Generally, curing is conducted for concrete immediately after casting in a humid environment in order to promote the hydration of cement paste. However, external curing water cannot reach the inside of concrete sufficiently, especially in concrete with a low water to cement ratio (W/C) because the surface part of such a type of concrete is dense. To compensate for such a problem, internal water curing is effective to promote hydration. Internal curing is a curing method in which part of the aggregate is replaced with saturated internal curing material to supply internal water into the cement paste continuously. In concrete, capillary water is consumed for hydration of

* Corresponding author : kkawai@hiroshima-u.ac.jp 
cement and the relative humidity in cement paste decreases. Internal curing water is supplied to the cement paste resulting from this humidity gradient.

As an internal curing material, lightweight aggregate (LWA) or super absorbent polymer particle (SAP) has been used in previous studies. It has been reported that these internal curing materials can make the pore structure of concrete denser and improve the strength and durability of the concrete [1-5]. However, some studies indicated that the compressive strength of concrete with LWA or SAP was the same as or lower than the reference concrete [1-4]. The lower strength of concrete with LWA can be caused by the high crushing value of LWA $[3,4]$.

Porous ceramic roof-tile waste aggregate (PCA) is also studied as an internal curing material. A kind of roof tile, "Sekisyu Kawara", is produced in the Chugoku district of Japan - about 150,000 tons per year - and approximately 10\% of Sekisyu Kawara is demolished due to thermal cracking and expected to be recycled. The PCA has a relatively high-water absorption of around 9\% and a crushing value of around 20\%, which are intermediate values between LWA and natural aggregate. Previous studies reported that PCA can lead to an increase in the compressive strength of concrete, the reduction of autogenous shrinkage in concrete and the improvement of shear strength of reinforced concrete beams [6-9]. However, the effects of PCA on compressive strength and autogenous shrinkage in previous researches are different with regards to the experimental conditions [7,8] and have not been evaluated sufficiently. Therefore, the present study aimed to investigate the effect of internal water supplied from PCA microscopically. A compressive strength test of concrete with PCA was conducted, and the microhardness of the cement paste around the aggregate in the concrete was also measured in order to investigate the extent of the influence of internal curing water supply.

\section{Experimental programs}

\subsection{Materials and mixture proportions}

Table 1 lists the properties of the materials used in the present study. Portland blastfurnace slag cement type B (BB), which contains 30-60\% blast furnace slag, was used as cement. Porous ceramic fine aggregate (PCFA) and porous ceramic coarse aggregate (PCCA) were used as internal curing materials in a saturated surface-dry condition after being immersed in water for 7 days.

Table 2 tabulates the mixture proportions for the 6 types of concrete prepared in this study. The W/C of all mixtures was 0.35 . A mixture proportion named BBC is the reference concrete to compare with other concretes using PCA. Mixtures G10 and G20 denote concretes in which the replacement ratios of PCCA are $10 \%$ and $20 \%$ in volume, respectively, while mixtures S14 and S27 denote concretes in which the replacement ratios of PCFA are $14 \%$ and $27 \%$ in volume, respectively. Moreover, 14 vol.\% of fine aggregate and 10 vol.\% of coarse aggregate are replaced with PCFA and PCCA, respectively, in G10S14. In the above mixtures, the amount of internal curing water in G10 and S14 was $7 \mathrm{~kg} / \mathrm{m}^{3}$, while that in G20, S27 and G10S14 was $14 \mathrm{~kg} / \mathrm{m}^{3}$. 
Table 1. Material properties.

\begin{tabular}{|c|c|c|c|}
\hline Materials & Type & Properties & Notation \\
\hline Cement & $\begin{array}{l}\text { Portland blast } \\
\text { furnace slag } \\
\text { cement-Type B }\end{array}$ & $\begin{array}{c}\text { Density: } 3.04 \mathrm{~g} / \mathrm{cm}^{3} \\
\text { Specific surface area: } 3710 \mathrm{~cm}^{2} / \mathrm{g}\end{array}$ & BB \\
\hline \multirow{2}{*}{$\begin{array}{c}\text { Fine } \\
\text { aggregate }\end{array}$} & Crushed quartz & $\begin{array}{c}\text { Density in saturated surface-dry condition: } \\
2.61 \mathrm{~g} / \mathrm{cm}^{3} \\
\text { Water absorption: } 1.04 \% \\
\text { Maximum size: } 5 \mathrm{~mm} \\
\end{array}$ & S \\
\hline & $\begin{array}{c}\text { Porous ceramic fine } \\
\text { aggregate }\end{array}$ & $\begin{array}{c}\text { Density in saturated surface-dry condition: } \\
2.28 \mathrm{~g} / \mathrm{cm}^{3} \\
\text { Water absorption: } 9.75 \% \\
\text { Size: } 1-5 \mathrm{~mm}\end{array}$ & PCFA \\
\hline \multirow{2}{*}{$\begin{array}{c}\text { Coarse } \\
\text { aggregate }\end{array}$} & Crushed gravel & $\begin{array}{c}\text { Density in saturated surface-dry condition: } \\
2.62 \mathrm{~g} / \mathrm{cm}^{3} \\
\text { Water absorption: } 0.67 \% \\
\text { Maximum size: } 20 \mathrm{~mm} \\
\end{array}$ & G \\
\hline & $\begin{array}{l}\text { Porous ceramic } \\
\text { coarse aggregate }\end{array}$ & $\begin{array}{l}\text { Density in saturated surface-dry condition: } \\
2.26 \mathrm{~g} / \mathrm{cm}^{3} \\
\text { Water absorption: } 9.08 \% \\
\text { Maximum size: } 13 \mathrm{~mm}\end{array}$ & PCCA \\
\hline
\end{tabular}

Table 2. Mixture proportions.

\begin{tabular}{|c|c|c|c|c|c|c|c|c|c|c|}
\hline \multirow{3}{*}{$\begin{array}{l}\text { Name of } \\
\text { specimen }\end{array}$} & \multirow{3}{*}{$\mathrm{W} / \mathrm{C}$} & \multirow{3}{*}{ s/a } & \multicolumn{8}{|c|}{ Unit mass $\left(\mathrm{kg} / \mathrm{m}^{3}\right)$} \\
\hline & & & \multirow{2}{*}{$\mathrm{W}$} & \multirow{2}{*}{ BB } & \multicolumn{3}{|c|}{ Fine aggregate } & \multicolumn{3}{|c|}{ Coarse aggregate } \\
\hline & & & & & Total & $\mathrm{S}$ & PCFA & Total & $\mathrm{G}$ & PCCA \\
\hline BBC & \multirow{6}{*}{0.35} & \multirow{6}{*}{0.403} & \multirow{6}{*}{170} & \multirow{6}{*}{486} & 658 & 658 & 0 & 977 & 977 & 0 \\
\hline G10 & & & & & 658 & 658 & 0 & 964 & 880 & 84 \\
\hline G20 & & & & & 658 & 658 & 0 & 951 & 781 & 170 \\
\hline S14 & & & & & 647 & 569 & 78 & 977 & 977 & 0 \\
\hline S27 & & & & & 635 & 480 & 155 & 977 & 977 & 0 \\
\hline G10S14 & & & & & 647 & 569 & 78 & 964 & 880 & 84 \\
\hline
\end{tabular}

\subsection{Curing condition}

Specimens were covered with aluminium adhesive tape and wet fabric immediately after casting to avoid water evaporation. All specimens were demolded at the age of 7 days and cured at $20 \pm 1^{\circ} \mathrm{C}$ and $60 \pm 5 \%$ R.H.

\subsection{Testing procedure}

\subsubsection{Compressive strength}

The compressive strength test was carried out at the ages of $1,3,7,28$, and 91 days in accordance with JIS A 1108, in which cylindrical specimens measuring $100 \mathrm{~mm}$ in diameter and $200 \mathrm{~mm}$ in height were used. 


\subsubsection{Microhardness}

Ten-centimeter cubic specimens were used for microhardness measurement. Each specimen was cut with an oil cutter to prepare 4-mm-thick plate samples at the ages of 1 and 3 days as shown in Fig.1. All plate samples were soaked in acetone in a vacuum deaeration apparatus to stop hydration, and then each specimen was cleaned with propanol for more than 15 min by using an ultrasonic cleaner to remove contaminations on its surface. After that, they were dried for 24 hours in a vacuum desiccator and stored in airtight containers with silica gel and soda lime.
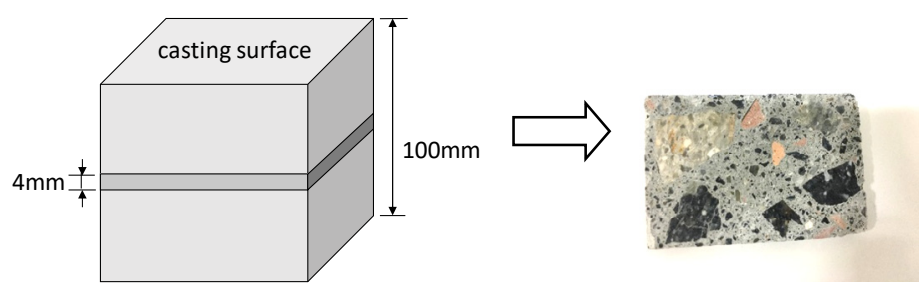

Fig. 1. Preparation of specimens.

The hardness of the cement paste at distances of 10-500 $\mu \mathrm{m}$ from the surface of PCA or $G$ was measured with a micro Vickers hardness testing machine. The Vickers hardness is calculated from the size of the diamond-shape indentations which are formed on the surface. The hardness at each distance is the mean value of 6 measurements within a standard deviation of 3.0.

\section{Results and discussions}

\subsection{Compressive strength}

Fig.2 shows the compressive strength of each concrete, and Fig.3 shows the compressive strength normalized by BBC as the reference concrete. BBC, G10 and S14 are shown with solid lines, and G20, S27 and G10S14 are shown with dotted lines. As seen in these figures, the compressive strengths of the 5 types of concrete with PCA are higher than BBC after the age of 3 days. G20 showed the largest compressive strength in this study and it was more than 20\% higher than BBC at the age of 91 days. On the other hand, the compressive strength of the other 4 types of concrete with PCA at the age of 91 days were almost the same and $10 \%$ higher than BBC. Although the amount of internal curing water in each concrete of G20, S27 and G10S14 was the same, the compressive strengths of S27 and G10S14 were smaller than that of G20. This result may be caused by the differences in how and when the internal curing water moves out from the PCA due to the size and combination of PCA.

As shown in Fig.3, the compressive strengths of G10, G20 and G10S14 with PCA at the age of 1 day was lower than that of BBC and the normalized values varied from 0.8 to 1.1. However, at the age of 3 days, the compressive strength of concrete with PCA was higher than that of BBC and the normalized values were more than 1.0. After 28 days, they exceeded 1.1. Therefore, though the internal curing water supply has little 
effect on the compressive strength of concrete at the age of 1 day, a greater effect can be seen from the age of 3 days.

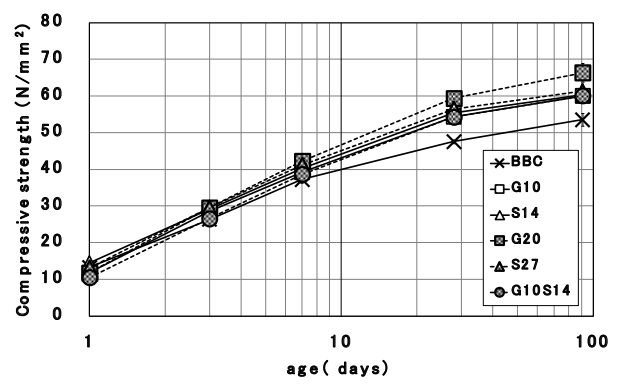

Fig. 2. Compressive strength of each concrete.

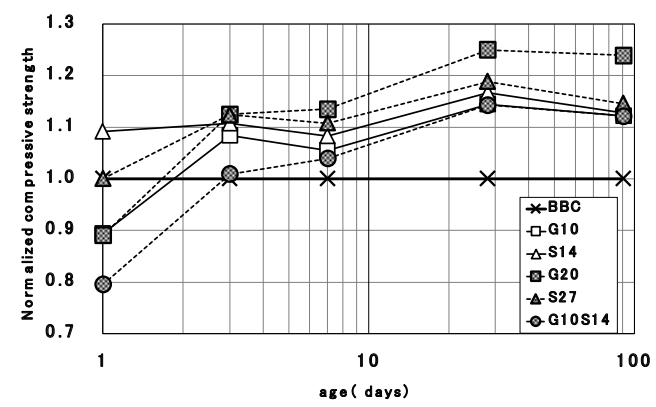

Fig. 3. Compressive strength of each concrete normalized by reference concrete (BBC).

\subsection{Microhardness}

From the results of the compressive strength test in 3.1, the effects of internal curing water supply at early ages were investigated microscopically by comparison of the microhardness of the cement paste around G in BBC and PCCA in G10. The results of the measurements at the ages of 1 day and 3 days are shown in Figs. 4 and 5, respectively.

Generally, an interfacial transition zone (ITZ) is formed around aggregate in concrete. ITZ is a discontinuous site and a defect with many capillary pores and microcracks and has a lower strength than aggregate and other cement paste. It has been known that ITZ reduces the strength of hardened concrete [10]. As shown in Fig.4, the hardness at distances of 10-300 $\mu \mathrm{m}$ from the surface of G and PCCA was only half of that at distances of more than $300 \mu \mathrm{m}$ at the age of 1 day in both types of concrete. The ITZ can be seen around G in BBC and PCCA in G10 at the age of 1 day, and its thickness was approximately $300 \mu \mathrm{m}$. On the other hand, as shown in Fig.5, at the age of 3 days, the hardness for G10 was almost the same regardless of the distance from the PCCA, while a lower hardness at the distances of 10-200 $\mu \mathrm{m}$ was seen in BBC. The ITZ around the PCCA in G10 at the age of 3 days did not exist as clearly as that around G in $\mathrm{BBC}$ at the same age.

The ITZ might be filled with cement hydrates produced by internal curing water supply from the PCA. The improvement of the ITZ leads to an increase in the compressive strength of concrete as shown in Figs.2 and 3. In this study, the reason for the higher hardness in BBC than G10 at a deeper distance than the ITZ is still unknown. Further investigation on this will be needed. 


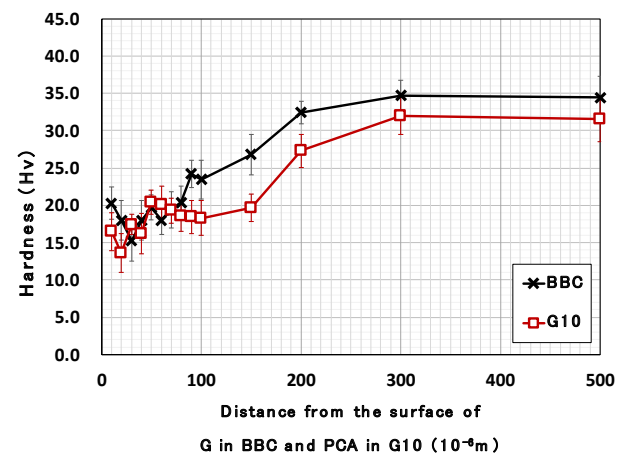

Fig. 4. Hardness of cement paste around $\mathrm{G}$ in $\mathrm{BBC}$ and PCA in G10 at the age of 1day.

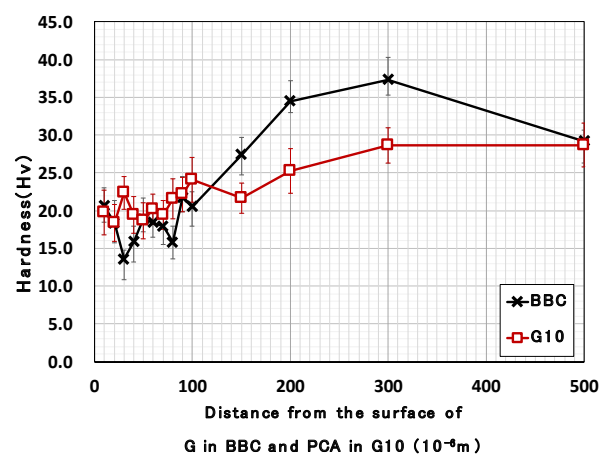

Fig. 5. Hardness of cement paste around $\mathrm{G}$ in $\mathrm{BBC}$ and PCA in G10 at the age of 3days.

\section{Conclusions}

The present study investigated the effect of the internal curing water supply from PCA on the compressive strength and microhardness of concrete. The following conclusions can be drawn from the experimental results in this study.

1) The compressive strength of concrete with PCA is higher than BBC. In particular, the compressive strength of G20 is more than 20\% higher than BBC at the age of 91 days and the highest of the concretes with PCA. This result shows that the effect of internal curing water on the compressive strength of concrete is different in the supplying method, even though the amount of internal curing water is the same.

2) The ITZ can be confirmed from the hardness around aggregate at the age of 1 day and its thickness is approximately $300 \mu \mathrm{m}$. However, at the age of 3 days, the ITZ in G10 does not exist clearly, while the thickness of the ITZ in BBC is about 200 $\mu \mathrm{m}$.

Consequently, this study shows the possibility that the internal curing water supply improves the microhardness of the ITZ around PCA. The improvement of the ITZ leads to an increase in the compressive strength of concrete.

\section{References}

1. A. Bentur, S. Igarashi, K. Kovler, Cement and Concrete Research 31, 1587-1591, (2001)

2. D. Shen, M. Wang, Y. Chen, T. Wang, J. Zhang, Construction and Building Materials 144, 717-727, (2017)

3. F. Wang, Y. Zhou, B. Peng, Z. Liu, S. Hu, ACI Materials Journal, 123-127, (2009)

4. M.T. Hasholt, O.M. Jensen, K. Kovler, Construction and Building Materials, 31, 226230, (2012)

5. D. Snoeck, O.M. Jensen, N.D. Belie, Cement and Concrete Research 74, 59-67, (2015) 
6. M. Suzuki, M.S. Meddah, R. Sato, Cement and Concrete Research 39, 373-381, (2009)

7. R. Sato, A. Shigematsu. T. Nukushina, M. Kimura, Journal of Materials in Civil Engineering, ASCE, 23, 777-782, (2011)

8. M.M. Macharia, R. Sato, A. Shigematsu, H. Onishi, Proceedings of JCI, 33, 113-118, (2011)

9. A. Fujiyama, M.M. Macharia, Y. Ogawa, K. Kawai, R. Sato, SCMT4, 591-600, (2016)

10. H. Uchikawa, S. Hanehara, D. Sawaki, CAJ Proceedings of Cement \& Concrete, 44, 330-335, (1990) 